\title{
Chapter 20 \\ Potential Impacts of Yield-Increasing Crop Technologies on Productivity and Poverty in Two Districts of Ethiopia
}

\author{
Bekele Hundie Kotu and Assefa Admassie
}

\begin{abstract}
Ethiopian agriculture is characterized by low productivity which has contributed to the persistence of food insecurity and poverty in the country. Reports indicate that several yield-increasing technologies are available but have not yet been adequately utilized. This chapter assesses the potential impact of yieldincreasing crop technologies on productivity and poverty based on the data collected from two districts in Ethiopia. We focus on the use of improved seeds, together with appropriate agronomic packages such as chemical fertilizers and row planting technique. Results suggest that the resulting monetary gains would be enough to lift the "better-off" poor households out of poverty, but they would not be enough to lift up the ultra-poor out of poverty, implying that other livelihood strategies are desirable for improving the well-being of the latter.
\end{abstract}

Keywords Agricultural productivity - Food insecurity - Yield-increasing technologies • Ex-ante assessment • Poverty

\section{Introduction}

In his lecture when accepting the 1979 Nobel Prize in Economics, T.E. Shultz posited "... [m] ost of the world's poor people earn their living from agriculture, so if we knew the economics of agriculture, we would know much of the economics of being poor." This is a worthy statement for scholars, practitioners, and

\footnotetext{
${ }^{1}$ see http://www.nobelprize.org/nobel_prizes/economic-sciences/laureates/1979/schultz-lecture. html.

B.H. Kotu $(\bowtie)$

International Institute of Tropical Agriculture, Tamale, Ghana

e-mail: bekelehu@yahoo.com
}

\author{
A. Admassie \\ Ethiopian Economic Association Yeka, Addis Ababa, Ethiopia \\ e-mail: aadmassie@yahoo.com
}


policymakers focusing on poverty reduction, and is quite relevant to be considered in regard to Ethiopia because of the fact that agriculture is the dominant sector in the Ethiopian economy and because poverty is mainly a rural phenomena in Ethiopia. ${ }^{2}$ In fact, agriculture has a strong multiplier effect on the current economy and, if nurtured to grow fast, will have a better impact on poverty than other sectors (Diao et al. 2010). Such a comparative advantage of agriculture has been recognized by the governments of Ethiopia at different times since the 1980s (and even before), although policy interventions couldn't always produce positive outcomes as desired. In fact, policy interventions prior to 2001 couldn't bring substantial changes in agriculture and, hence, in poverty levels in rural areas. The total production of cereal crops was stagnant during the 1980s due to stagnant yield levels (Hundie 2012). While the growth in production was substantial (i.e., $6.6 \%$ ) in the 1990s, the source of growth was expansion of agricultural lands to marginal areas. However, average yield levels have been rising since 2003, resulting in a rapid growth of output (i.e., $7.5 \%$ of average annual growth in cereal production between 2003 and 2012) (ibid). This is a desirable result which implies the success of the national policies during this period. ${ }^{3}$

Nevertheless, the average yield of staple food crops in Ethiopia is still low, which has contributed to the persistence of poverty in the country's rural areas. For instance, wheat yield at $2 \mathrm{Mt} / \mathrm{ha}$ is $65 \%$ below the average of the best African region (i.e., Southern Africa) and $260 \%$ below the average of the best world region (i.e., Western Europe) (FAOSTAT 2013). The low yield observed among the staple crops is mainly attributed to low use of improved technologies. Evidence shows that only $7.3 \%$ of the area under cereals was planted with improved varieties in 2010/2011 (CSA 2011a, b). While maize is far better than the other crops in terms of percentage of area under improved varieties (28\%), the adoption rate is still low as compared to several countries in eastern and southern Africa, such as Zimbabwe (80\%), Zambia (75\%), Kenya (72\%), and Uganda (35\%) (ATA 2012).

On the other hand, a large number of improved varieties are available which can be used to increase productivity. More than 700 improved crop varieties are ready for use together with their agronomic packages (MoA 2011). About 70 were released recently (i.e., in 2011). Grain crops are dominant in terms of the total number of improved seeds, constituting about $68 \%$ of the technologies. Among the grain crops, cereals account for about $56 \%$ of the total varieties corresponding to that category, followed by pulses $(30.6 \%)$ and oil crops $(13.8 \%)$. Cereals are dominated by wheat, ${ }^{4}$ constituting about $31 \%$ of the total varieties in that category, whereas

\footnotetext{
${ }^{2}$ For instance, considering that poverty rates in rural and urban areas are $30.4 \%$ and $25.7 \%$, respectively (MoFED 2012), and given that more than $80 \%$ of the Ethiopian population live in rural areas, it is possible to conclude that rural areas account for the majority of poor people in Ethiopia.

${ }^{3}$ The two national development strategies associated with this period are the Plan for Accelerated and Sustainable Development of End Poverty (PASDEP) (2004/2005-2009/2010) and the Growth and Transformation Plan (GTP) (2010/2011-2014/2015).

${ }^{4}$ Wheat constitutes bread wheat, durum wheat, emmer wheat, and buck wheat.
} 
maize $(16.2 \%)$, barley $^{5}(14.7 \%)$, sorghum (12.9\%), tef (11.5\%), rice ${ }^{6}(7.2 \%)$, millet $^{7}(4 \%)$, and others $(1.8 \%)$ take consecutive ranks in that order (MoA 2011).

While agricultural growth is an important means for reducing poverty in rural areas of developing countries, marginality is cited as a root cause of extreme poverty (Gatzweiler et al. 2011; von Braun et al. 2009; Ahmed et al. 2007). This is because of the fact that marginality implies the presence of a set of constraints which need to be lifted in order to recognize the capabilities of people and transform them into functioning actors (Gatzweiler et al. 2011). Thus, focusing on marginal areas would be a good strategy to be followed in order to bring a substantial reduction of extreme poverty in rural areas of developing countries, which might also apply to the Ethiopian case. However, the level of contributions of agriculture to poverty reduction may not be evenly distributed across all marginalized areas where agriculture is practiced as a means of livelihood. Intuitively speaking, its contribution would be high where the potential is high and could decline as potential declines due to relatively low/high costs of production in high/ low potential areas.

Therefore, this research was initiated with the purpose of assessing the potential contribution of the adoption of yield-increasing crop technologies (YICT) to household poverty in marginalized areas characterized by high potential of agriculture. While several technologies could increase crop yield, we consider here the use of improved seeds together with appropriate agronomic packages, such as chemical fertilizers and row planting technique. The remainder of the paper is divided into five sections. Sections "Impacts of Agricultural Technologies" and "Time and Adoption" review literature on the impacts of YICT and the time dimension of adoption. Section "Methods of the Study" describes the methods used for the study, including selection of the study areas and households, sources of data, and methods of data analysis. Section "Household Strata" describes the household strata with regards to income poverty. Section "Potential Impacts of the Introduction of the Technologies" presents the potential impacts of existing YICT on poverty among different strata of households. The last section concludes the paper.

\section{Impacts of Agricultural Technologies}

Technologies are important sources of productivity growth in agriculture, thereby leading to better income and lower poverty. ${ }^{8}$ This was observed practically in Asia and parts of South and Central America during the so-called "Green Revolution" era in the

\footnotetext{
${ }^{5}$ Barley constitutes food barley and malt barley.

${ }^{6}$ Rice constitutes irrigated type and upland type.

${ }^{7}$ Millet constitutes finger millet and pear millet.

${ }^{8}$ See, for instance, Nomaan Majid, Reaching Millennium Goals: How well does agricultural productivity growth reduce poverty? ILO Employment Strategy Department, 2004/2012.
} 
1960s and 1970s. An important manifestation of the green revolution was the adoption of YICT such as improved seeds, chemical fertilizers and pesticides, along with expansion of infrastructure such as irrigation, roads and electricity. The widespread adoption of scientific agricultural techniques during this period resulted in a rise in labor productivity, thereby increasing income and reducing poverty (Hazell 2009).

Studies on post GR impacts in different countries also show that improved agricultural technologies have positive impacts on yield level and variability, income, and food security, as well as poverty (Macharia et al. 2012; Krishna and Qaim 2008; Napasintuwong and Traxler 2009; Hareau et al. 2006, Qaim 2003). Macharia et al. (2012) assessed the potential economic and poverty impacts of 11 improved chickpea varieties in Ethiopia using the economic surplus approach. They found that the new technologies can generate a total of \$111 million (US) for 30 years, which could lift more than 0.7 million people (both producers and consumers) out of poverty. Krishna and Qaim (2008) studied the potential impacts of Bt eggplant on economic surplus and farmers' health in India. The results show that the technology can significantly reduce insecticide applications and increase effective yields while generating an economic surplus of about $\$ 108$ million (US) per year, which could be harnessed by diverse economic groups, including resource-poor farmers. The ex-ante analysis on the benefits of herbicide-resistant transgenic rice in Uruguay using a stochastic simulation technique show that the technologies would generate a benefit of $\$ 1.82$ million (in terms of mean net present value) for producers and $\$ 0.55$ million for the multinational corporations who develop the technologies (Hareau et al. 2006). Napasintuwong and Traxler (2009) estimated that total economic surplus of the adoption of GM papaya in Thailand is in the range of $\$ 650$ million to $\$ 1.5$ billion, which would be generated within the first 10 years of adoption. The primary beneficiaries would be small-scale papaya farmers, who would benefit even with the loss of export markets.

\section{Time and Adoption}

Adoption of technologies may not take place overnight. Rather, it is a process that occurs over time. Davies (1979) posits that adoption starts with innovators and expands via early adopters, early majority, and late majority, finally ending with laggards. Studies by Mosher (1979), Rogers (1983), Mahajan and Peterson (1978), and Bera and Kelley (1990) associate variations observed among households in adoption decisions to variations in the capacity of households to acquire and process information, as well as differences in resource constraints. The distribution of total net benefit from adoption of the new technology depends on the adoption path. However, adoption rates are highly uncertain in ex-ante analysis and empirical results are rarely available for consumption. The difficulty of fixing ex-ante values arises from the fact that many factors affect both the adoption path and the maximum rate of adoption. Despite variable adoption patterns that might exist, Alston et al. (1995) suggest sigmoid curves for adoption paths in ex-ante studies, which is what we have adopted in our analysis. 
The aggregate net benefit generated from adoption of improved technologies depends on the maximum achievable rate of adoption and the speed of adoption. Indeed, these are important for assessing the impacts of the technologies, taking into account the time dimension of adoption. The first challenge to this exercise is fixing the maximum achievable adoption rate. While results are variable depending on the nature of technologies and other contexts, empirical studies indicate that adoption rate of improved technologies of cereals can be $90 \%$ or more (Ephraim and Featherstone 2001; Motuma et al. 2010; Hailu 2008). For instance, Ephraim and Featherstone (2001) reported a $90 \%$ adoption rate for improved maize varieties in Tanzania, while, more recently, Motuma et al. (2010) reported an adoption rate of $92 \%$ in one district of central Ethiopia. Similarly, Hailu (2008) reported that nearly $90 \%$ of the farmers in central Ethiopia adopted improved wheat varieties and associated technologies.

A few studies are available to fix ideas regarding the speed and pattern of adoption of crop technologies. Tesfaye et al. (2001) showed that it took about 30 years to reach an adoption rate of about $90 \%$ in northwestern Ethiopia. That study revealed a sigmoid pattern of adoption whereby about $80 \%$ of the total change was attributed to the last 10 years. However, the speed of adoption can be influenced by external intervention such as good extension services and, hence, the maximum length of time to reach the maximum rate of adoption can be shortened (Tesfaye et al. 2001; Hundie et al. 2000; Motuma et al. 2010). For example, Tesfaye et al. (2001) noted that, while the rate of adoption of improved wheat varieties has increased from about nil to $72 \%$ within 20 years in Ethiopia, most of the changes occurred within 6 years after the extension system had been strengthened. Similarly, other studies (e.g., Hundie et al. 2000; Motuma et al. 2010; Hailu 2008) show that extension services have significant effect on adoption.

\section{Methods of the Study}

\section{Selection of Marginality Hotspot Districts (Woredas)}

Marginality hotspots are rural areas in which high prevalence of poverty and high agricultural potential overlap (Graw and Ladenburger 2012). Based on Gatzweiler et al. (2011), marginality is defined as "an involuntary position and condition of an individual or group at the margins of social, political, economic, ecological and biophysical systems, preventing them from access to resources, assets, services, restraining freedom of choice, preventing the development of capabilities, and eventually causing extreme poverty" (2011, p. 3). We used a two-step procedure to identify the woredas for study. First, marginality hotspots were identified based on the work of Graw and Ladenburger (2012), which classifies areas in Ethiopia with respect to marginality levels. Out of seven levels of marginality identified in 
that paper, ${ }^{9}$ we selected areas marginalized in terms of four dimensions or more based on a visual assessment of the marginality hotspot map. ${ }^{10}$ These include 37 woredas (15 in the Amhara region and 22 in SNNPR). These woredas represent a number of the country's different agro-ecologies, and, hence, they are diverse in terms of farming systems, i.e., cereal-based, perennial-crop-based, and livestockbased pastoral areas. We focused on cereal-based farming systems, specifically on those areas producing the four major cereals in Ethiopia, teff, maize, sorghum, and wheat. This was done for the sake of maximizing the benefit of a focused analysis. ${ }^{11}$ Moreover, cereals were focused on due to the fact that they are dominant sources of calories and income among Ethiopian smallholders and, hence, their contribution to food security is quite substantial. A total of 17 cereal-based woredas were identified, out of which 15 are from the Amhara region and 2 are from SNNPR.

The second parameter considered to identify the study areas was agricultural potential. Precipitation was used as a proxy variable to measure agricultural potential. Thus, all drought-prone woredas were excluded, which resulted in 11 woredas. $^{12}$ The woredas lacking information on precipitation level were also excluded. The remaining six woredas (4 from the Amhara region and 2 from SNNPR) were prioritized based on their market access. ${ }^{13}$ Two woredas from the Amhara region and 1 woreda from SNNPR were dropped since they have better market access, which resulted in 2 woredas from the Amhara region (Debre Sina/ Borena in the South Wollo zone and Baso Liben in the East Gojam zone) and one woreda from SNNPR (Halaba special woreda). These woredas are characterized by high prevalence of poverty and marginality, as characterized by Graw and Ladenburger (2012) and by high agricultural potential. Finally, Baso Liben and Halaba were selected for our study while Debre Sina was dropped because of its lower potential in cereal production than Baso Liben. Figure 20.1 displays the location of the study areas.

\section{Selection of Subdistricts (Kebeles)}

Both marginality and agricultural potential were considered in selecting kebeles. However, our sampling at this stage was dependent on local knowledge and less

\footnotetext{
${ }^{9}$ The dimensions considered in Graw and Ladenburger (2012) are: (1) economy, (2) demography, (3) landscape design, land use and location (spatial variables), (4) behavior and quality of life, (5) ecosystem, natural resources and climate, (6) infrastructure, (7) public domain and institutions.

${ }^{10}$ The detailed maps used to identify marginality hotspots were obtained from ZEF (courtesy of Christine Hausmann).

${ }^{11}$ However, cereal-based systems are not devoid of livestock and perennial crops and, hence, the possibility that farm households can be directed toward the latter options can be assessed.

${ }^{12}$ The data on moisture status at the woreda level was obtained from IFPRI-ESSP II (courtesy of Dr. Alemayehu Seyoum Tafesse).

${ }^{13}$ The data on market access at the woreda level was obtained from IFPRI-ESSP II.
} 


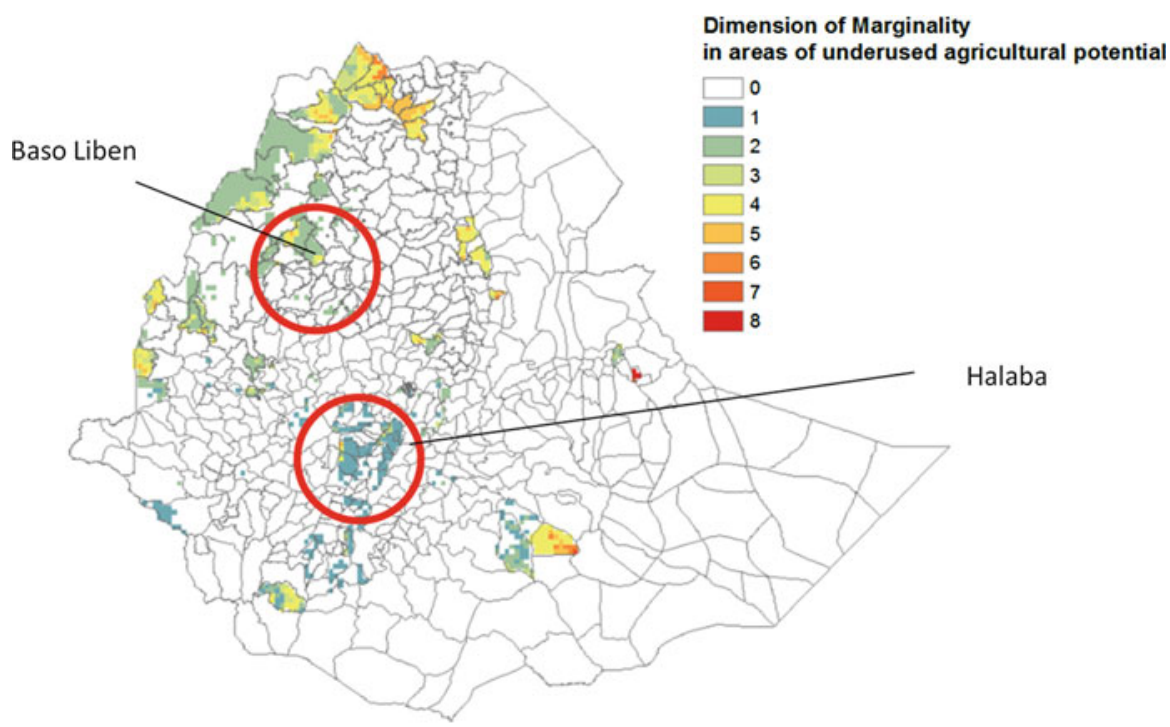

Fig. 20.1 Location of the study woredas in Ethiopia

sophisticated variables, since we couldn't find a readymade dataset to locate marginality hotspots at the kebele level. Marginality was proxied by the distances of kebeles from woreda towns, whereas agricultural potential was proxied by a composite of parameters such as amount and reliability of rainfall, irrigation potential, soil fertility, and topographic characteristics. Assessments of the kebeles against these parameters were made by agricultural experts from the selected woredas. The sampling involved several steps. First, all cereal-based kebeles were identified and put under three categories (nearby, medium, and far) based on their distance from woreda towns. Kebeles more than $10 \mathrm{~km}$ away from woreda administrative centers were put under the "far" category, and, hence, were considered to be marginalized. Second, kebeles were put under three groups based on agricultural potential (i.e., high potential, medium potential, and low potential); the categorization was done based on assessments made by experts at woreda offices of agriculture, taking into account the factors listed earlier. Third, a new list of kebeles was developed constituting marginalized kebeles and those having high agricultural potential. Last, three cereal-based kebeles (mainly growing wheat, teff, and maize) were purposively selected based on their accessibility for conducting the household survey.

\section{Selection of Households}

Households were stratified based on two parameters, namely landholding and gender of household head. Land is traditionally used as a stratifying 
variable due to the fact that it is a crucial asset among Ethiopian smallholder farmers. ${ }^{14}$ Gender was used because one can easily obtain gender disaggregated lists from secondary sources, and gender is one of the key factors related to poverty. The selection process involved three steps. First, households were grouped into three categories based on landholding: bottom category $(<34 \%)$, medium category (34-66 \%), and upper category $(>66 \%)$. Second, each stratum was stratified again into two sub-strata based on the gender of household heads. Third, sample households were drawn from each sub-stratum using a proportionate-to-size sampling technique such that the total number of sample households in each stratum would be 20 . The entire process of sampling resulted in a total of 360 sample households.

\section{Post-survey Re-stratification of Households}

The sample households were re-stratified after the survey based on income level. Income level is used as a measure of living standard. Basically, the households earn income from three different sources, namely: crop production, livestock production, and off-farm activities. Expenses for commercial inputs such as fertilizer, improved seeds, chemicals, machinery rents, and hired labor were deducted from income from crop production. The purchasing power parity (PPP) exchange was used to convert the income into USD. ${ }^{15}$ The total income of each household was converted into per capita income (PCI) per day, which was used to stratify households into four strata, namely: (1) better-off households (those who earn a PCI of at least $\$ 1.92 /$ day); (2) subjacent poor (those with income between \$1.54/day and \$1.92/day); (3) medial poor (those with income between $\$ 1.15 /$ day and $\$ 1.54 /$ day); and (4) ultra poor (those who earn less than $\$ 1.15 /$ day). ${ }^{16}$

In addition to the above method, stratification was done by using self-reported data gathered from the sample respondents on their households' wealth status. In this regard, respondents were asked to position their households within the above four strata, taking

\footnotetext{
${ }^{14}$ The other important asset is livestock, but this doesn't lend itself for use in the sampling process of rural household surveys due to the absence of secondary data on livestock ownership at the household level. Thus, we did not consider it in our sampling process.

${ }^{15}$ According to the IMF World Economic Outlook, the Implied PPP conversion rate for Ethiopia at the end of 2012 was 7.04 (http://www.quandl.com/IMF-International-Monetary-Fund/MAP WEO_IMPCR_ETH-World-Economic-Outlook-Implied-PPP-Conversion-Rate-Ethiopia) (accessed on 28/03/2013). A slightly different rate (i.e., 7.2) is implied in http://www.indexmundi. com/ethiopia/economy_profile. We adopted the rate implied in the World Economic Outlook.

${ }^{16}$ According to the project manual, the stratification goes like this: subjacent poor are those with incomes between $\$ 1$ and $\$ 1.25 /$ day, medial poor: between $75 \notin$ and $\$ 1 /$ day, and ultra-poor: below $75 \notin /$ day. We adjusted these cut-off values by considering the national poverty line, which was set to be 3,781 birr (or \$702) per annum in 2011 (PPP rate for 2011=5.389). We also added the better-off category to include households with daily PCI greater than the poverty line.
} 
into account other households in their kebeles. ${ }^{17}$ Such an introspective approach may be useful for capturing the objective reality of the households' conditions and their capabilities to mitigate or cope with various kinds of risks, since it gives room for the households to reflect on their household situation. Thus, results based on this stratification are supposed to supplement the findings regarding the income-based stratification.

\section{Methods of Data Analysis}

Adoption of the recommended technologies can be considered as a partial adjustment to households' crop enterprises. Thus, a partial budget approach was used to elicit the potential income impacts of adopting the technologies. Four important adjustments are expected to occur due to the introduction of new technologies. These are: (1) increased benefits, (2) reduced costs, (3) increased costs, and (4) forgone/reduced income. The first two constitute changes in revenue as a result of adopting the technologies, whereas the last two constitute changes in costs associated with the technologies.

The average net benefit per hectare from adopting a new YICT is given by

$$
N B_{j t}=P_{j t} \Delta Y_{j}-\Delta V C_{j t},
$$

where $N B_{j t}$ is the net benefit per hectare from crop $j$ in year $t, P_{j t}$ is the price of crop $j$ in year $t, \Delta Y_{j}$ is the yield gap of crop $j$ to be filled by applying the technology, and $\Delta V C_{j t}$ is the change in variable cost of production of crop $j$ per hectare due to the introduction of the technology.

$$
\Delta V C_{j t}=V C_{j t N}-V C_{j t T}
$$

where $V C_{j N}$ is the variable cost of production of crop $j$ per hectare under a new technology and $V C_{j T}$ is the variable cost of production of crop $j$ per hectare under the existing technology in year $\mathrm{t}$.

Computing net benefits per hectare for each year requires forecasted output and input prices for each year, which may be difficult to acquire. In that case, a simpler approach may be adopted, i.e., computing the net benefit per hectare for the base year based on the actual price information and adjusting it over time based on a forecasted average inflation rate. This may help to adjust for possible changes in costs of living over time. This can be done as follows:

$$
N B_{j t}=N B_{j 0}(1+r)^{t},
$$

where $r$ is an average annual inflation rate.

\footnotetext{
${ }^{17}$ For the sake of convenience during interview, the above four strata were defined as rich, intermediate, poor, and very poor.
} 
The total net benefit in year $t$ can be computed as:

$$
N B T_{j t}=A_{j t} N B_{j t},
$$

where $N B T_{j t}$ is the total net benefit of all famers applying the new technology to produce crop $j$ in year $t$, and $A_{j t}$ is the area under crop $\mathrm{j}$ planted with the new technology.

The distribution of total net benefit over time from adoption of the new technology depends on the adoption path. That is, we require the change of area under crop $j$ planted with the new technology and the rate of adoption over time. However, adoption rates are highly uncertain in ex-ante analysis and empirical results are rarely available for consumption. The difficulty of fixing ex-ante values arises from the fact that many factors affect both the adoption path and the maximum rate of adoption. Despite variable adoption patterns that might exist, Alston et al. (1995) suggest logistic curves for adoption paths in ex-ante studies. Following their suggestion,

$$
A_{j t}=f(t)=\frac{L}{1+b e^{-k t}},
$$

where $L$ is the expected maximum land to be allocated to improved technologies, $t$ is time, and $b$ and $k$ are constants.

Therefore, the total net benefit of all farmers adopting the technologies in a given year can be given by:

$$
N B T_{j t}=N B_{j 0} \frac{L}{1+b e^{-k t}}(1+r)^{t}
$$

The total net benefit over the entirety of adoption years $\left(N B G_{j}\right)$ is given by the cumulative of the above distribution:

$$
N B G_{j}=\int_{0}^{T} N B_{j 0} \frac{L}{1+b e^{-k t}}(1+r)^{t} d t,
$$

where $\mathrm{T}$ is the maximum number of years it takes to reach the maximum adoption level. The net present value of the aggregate net benefit over the years $\left(N B G_{p j}\right)$ can be computed as:

$$
N B G_{p j}=\int_{0}^{T} N B_{j 0} \frac{L}{1+b e^{-k t}}(1+r)^{t}(1+\rho)^{-t} d t
$$

where $\rho$ is the nominal discount rate. 
The total net present value of net benefits from adoption of YICT for the production of the three crops is, therefore,

$$
N B G_{p T}=\sum_{j=1}^{3} N B G_{p j}
$$

\section{Measuring Components of Net Benefit}

\section{Crop Price}

The average prices for each of the study districts were extracted from the household survey data of this study, which was conducted in February 2013. These prices were used as a base for the three crops. The average prices of maize, tef, and wheat are, respectively, 5.2, 10.5, and $6 \mathrm{birr} / \mathrm{kg}$ in Baso Liben, whereas the average prices of maize and tef are, respectively, 4.5 and $11.35 \mathrm{birr} / \mathrm{kg}$ in Halaba.

\section{Measuring Yield Gap}

We defined two levels of potential yields which led to two levels of yield gaps. ${ }^{18}$ The first one is based on the average grain yields of selected improved varieties, as reported in the national crop variety register, which is published by the Ministry of Agriculture every year (MoA 2011). In this regard, a variety known as BH 540 was considered to compute yield gaps of maize in Halaba, while BH 660 was used for Baso Liben. These varieties are under distribution in these areas. With regards to tef, two varieties, namely Quncho /Dz-Cr-387 (RIL-355)/ and Tseday (Dz-Cr-37), were considered in both areas. Since both varieties have not been distributed yet in the study areas, but are suitable varieties for distribution, we defined the potential yield as the average yield of these two varieties in both areas. A variety known as Kakaba (Picaflor) was considered for potential yield of wheat. The second type of yield gap was computed taking into account the average yields of the top $10 \%$ performing households. In this case, the average of top $10 \%$ of yield was computed for each of the selected crops and districts and used to assess the yield gaps.

Yields based on on-farm variety trials are superior to average yields attained by the top $10 \%$ performing farmers. On-farm variety trials are conducted under the

\footnotetext{
${ }^{18}$ Yield gaps can be defined as the difference between what is attainable and what is actually attained by the farmers. However, what is attainable (i.e., yield potential) can vary depending upon the level of definition yielding different types of yield gap. The first type of yield gap is the difference between what is theoretically conceived by scientists and what is attained at experimental stations. The second type of yield gap is the difference between yield at the experimental station and potential yield at farmers' yield, perhaps due to environmental conditions and technological differences between experimental stations and farms. The third (last) type is the difference between potential on farm yield and actual farmers' yields. We considered the third type of yield gap in our analysis.
} 
highest care of researchers and, hence, may be difficult to achieve in the short run by many poor farmers who lack capacities. ${ }^{19}$ Thus, such high yield levels can be taken as the upper boundary for comparing local achievements. On the other hand, the "top $10 \%$ " average yield has already been achieved by some farmers. However, some of these farmers might not have used recommended practices. Thus, the "top $10 \%$ " yield can be taken as the lower boundary for comparing achievements. Therefore, the "top $10 \%$ " average yield can be taken as the second best, while the "on-farm trial" yields can be taken as the first best targets for policymakers and practitioners at different levels.

\section{Computing Variable Costs}

Several variable costs are incurred in the process of crop production; costs incurred from labor, chemical fertilizers, oxen power, pesticides, seeds/planting materials, and rents of farm machineries are the major ones. However, not all of these are important in our partial budget analysis. Actually, we were interested in those costs which are affected due to the introduction of the new technologies. In this regard, we assumed that only seed and fertilizer costs would be affected due to the introduction of the new technologies under consideration. ${ }^{20}$ Prices of fertilizer and seeds prevailing in 2013 were used as a base.

\section{Household Strata}

Farming households were put under four strata based on the criteria discussed in section "Time and Adoption". Considering the income-based approach, about $10 \%$ of the households were categorized as better-off while the rest were put under the three "poor" categories, i.e., subjacent poor, medial poor and ultra-poor. Ultra-poor households constitute $71.4 \%$ of the total households, whereas the subjacent poor and the medial poor account for about $5.3 \%$ and $13.1 \%$, respectively. The mean per capita income for all households is $\$ 1.26 /$ day, which is below the national poverty line. ${ }^{21}$ The mean values for better-off, subjacent poor, medial poor, and ultra-poor households are $\$ 3.57, \$ 1.71, \$ 1.30$, and $66 \phi$, respectively. The F-test indicates that there is a significant difference among the four strata of households with regards to per capita income per day $(\mathrm{p}=0.000)$. Post hoc multiple

\footnotetext{
${ }^{19}$ Most of them are equivalent to average yields of developed countries.

${ }^{20}$ Row planting is expected to increase labor input during planting, but experts comment that it reduces labor input during weeding. Since its net effect has not yet been studied, we assumed that row planting wouldn't affect the aggregate labor input.

${ }^{21}$ The national poverty line is estimated at 3781 birr per person per annum (equivalent to $\$ 1.92$ per person per day using the PPP rate of 2012).
} 
comparisons show that better-off households are significantly better off than all other strata of households in terms of per capita income per day; ultra-poor households are also significantly different from all others from the lower side. However, the two strata in the middle of the poverty spectrum (i.e., the subjacent poor and the medial poor) do not differ significantly from each other.

Results based on the self-reported stratification show that $5.8 \%$ of households are within the category of better-off, while the rest of the households fall in the remaining three strata. The subjacent stratum takes the largest share, constituting $50.6 \%$ of the total households, which is followed by the medial poor $(36.9 \%)$. The ultra-poor constitute only $6.7 \%$ of the total number of households. The mean daily per capita income significantly varies among households in different strata. Betteroff households could earn about $\$ 2.05$ per day on a per capita basis. This is above the national poverty line set by the Ministry of Finance and Economic Development in 2010/2011 $1^{22}$ (MoFED 2012). The mean daily per capita income for the ultra-poor is about 53ф, which is about one fourth of the income of the better-off. The figures corresponding to the subjacent poor and the medial poor are $\$ 1.42$ and $\$ 1.05$. A post hoc multiple comparison test (using Tamhane's test) shows that better-off households are significantly different from the medial poor and the ultra-poor, but not different from the subjacent poor. On the other hand, the ultra-poor households are significantly lower than households in all other strata in terms of income. The two strata of poor households in the middle are not different from each other.

\section{Potential Impacts of the Introduction of the Technologies}

The direct potential effect of the intervention is that the yields of the target crops will grow substantially, resulting in a rise in total production that can be consumed and/or sold by the households. Here, we present the potential benefits disaggregated by the three target crops and by the household strata we have defined so far. In both cases, the analyses for the two locations were done separately.

\section{Potential Net Benefits by Crop Type}

The total net benefits for farmers from adopting the YICT by crop type and study district are presented in Table 20.1. The figures reported under the higher target case (HTC) are based on the assumption that smallholders would attain the average yields of the target crops equivalent to the average yields computed from on-farm

\footnotetext{
${ }^{22}$ The poverty line was set based on the data from Household Income and Consumption Expenditure Survey of 2010/2011 conducted by Central Statistical Agency of Ethiopia. The HICE survey covered 27,830 rural and urban households in the country.
} 
Table 20.1 Net benefit per hectare of land from YICT

\begin{tabular}{l|l|l|l|l|l|l|l|l}
\hline & \multicolumn{9}{l|}{ Halaba } & \multicolumn{2}{l}{ Baso Liben } \\
\hline & $\begin{array}{l}\text { NB, HTC } \\
\text { (Birr/ha) }\end{array}$ & $\begin{array}{l}\text { NB, LTC } \\
(\text { Birr/ha })\end{array}$ & $\begin{array}{l}\text { IRR, } \\
\text { HTC }\end{array}$ & $\begin{array}{l}\text { IRR, } \\
\text { LTC } \\
(\%)\end{array}$ & $\begin{array}{l}\text { NB, HTC } \\
(\text { Birr/ha })\end{array}$ & $\begin{array}{l}\text { NB, LTC } \\
(\text { Birr/ha })\end{array}$ & $\begin{array}{l}\text { IRR, } \\
\text { HTC }\end{array}$ & $\begin{array}{l}\text { IRR, } \\
\text { LTC } \\
(\%)\end{array}$ \\
\hline Maize & 18,024 & 3831 & 947 & 280 & 28,283 & 13,484 & 1844 & 931 \\
\hline Tef & 13,880 & 6820 & 827 & 457 & 6,513 & 8,319 & 434 & 527 \\
\hline Wheat & - & - & - & - & 22,601 & 12,335 & 3648 & 2036 \\
\hline
\end{tabular}

Note: $N B$ net benefit, IRR internal rate of return. HTC higher target case, LTC lower target case

variety trials. Those figures, which are reported under the lower target case (LTC), are based on the assumption that the current yield gaps between typical farmers and the most productive farmers (or the top $10 \%$ of productive farmers) would be eliminated. This latter target is in line with the current target of the Ethiopian government to scale up best practices (MoFED 2010).

The additional net benefit is highest for maize in both districts under the HTC. Under the HTC, smallholders could get as high as 18,000 birr per hectare of additional net benefit in Halaba; the figure in Baso Liben is higher by nearly $60 \%$. While wheat is not dominantly produced in Halaba, it ranks second in Baso Liben in terms of additional net benefit per hectare. The additional net benefit in the case of tef is lower than that of maize, as well as wheat. It is lower by about $23 \%$ in Halaba and by about $77 \%$ in Baso Liben as compared to maize. However, the benefit from adopting YICT is quite high even for tef, as indicated by the Internal Rate of Return (IRR). ${ }^{23}$

Benefits corresponding to the LTC are substantially lower than that of the HTC. The exception is the case of tef in Baso Liben. ${ }^{24}$ In Halaba, the net benefit under the LTC is about one-fifth of the figures corresponding to the HTC for maize, while it is about one half for tef. The net benefits corresponding to the LTC are about one half of the net benefit under the HTC for wheat and maize in Baso Liben. Nevertheless, the potential net benefits from YICT of the target crops are high in both districts, even under the LTC. The values of IRR reported in the table may confirm this assessment. Maize is the most rewarding crop in Halaba if technologies are adopted, followed by tef. Wheat takes the first rank in Baso Liben, while tef takes the second.

\section{Potential Net Benefits by Household Strata}

The distribution of the potential net benefit among households depends on the total size of land allocated for the target crops. Results are displayed in Table 20.2. The

\footnotetext{
${ }^{23}$ An IRR between $50 \%$ and $100 \%$ is supposed to be enough to adopt improved varieties and associated packages (CIMMYT 1988).

${ }^{24}$ The average of top $10 \%$ yield is greater than the average yield of on-farm variety trials.
} 
Table 20.2 Net benefit per household from YICT (Birr), by household strata

\begin{tabular}{l|l|l|l|l}
\hline & \multicolumn{2}{|l|}{ Halaba } & \multicolumn{2}{l}{ Baso Liben } \\
\hline & $\begin{array}{l}\text { Higher target } \\
\text { case }\end{array}$ & $\begin{array}{l}\text { Lower target } \\
\text { case }\end{array}$ & $\begin{array}{l}\text { Higher target } \\
\text { case }\end{array}$ & $\begin{array}{l}\text { Lower target } \\
\text { case }\end{array}$ \\
\hline Better-off & 24,273 & 4497 & 30,236 & 11,171 \\
\hline $\begin{array}{l}\text { Subjacent } \\
\text { poor }\end{array}$ & 18,131 & 3363 & 22,564 & 7976 \\
\hline Medial poor & 24,022 & 4457 & 18,982 & 6653 \\
\hline Ultra-poor & 14,262 & 2656 & 13,221 & 4618 \\
\hline Total & 17,216 & 3198 & 17,962 & 6386 \\
\hline
\end{tabular}

average net benefit per household under the HTC is about 17,000 birr in Halaba and nearly 18,000 birr in Baso Liben. The HTC yields more than five-fold higher benefits than that of the LTC in Halaba, while it yields about three-fold higher benefit than the LTC in Baso Liben. Under both targets, the benefits are not uniformly distributed among the four strata of households, i.e., better-off households would receive the highest benefit, while ultra-poor households would receive the lowest. The daily net per capita benefit from the adoption of YICT follows the same pattern as that of the net benefit per household, i.e., the highest benefit was computed for better-off households and the lowest for ultra-poor households in both districts and with respect to both targets.

\section{Potential Impacts on Poverty}

The average additional net benefit per household for each stratum was used to compute the potential impacts of the technologies on poverty after changing it to its dollar equivalent and computing per capita figures. Figures 20.2 and 20.3 display the potential impacts of the adoption of YICT on poverty reduction. If higher targets are achieved, households under the subjacent poor and the medial poor strata would be lifted up to the non-poor category in both districts. However, ultra-poor households remain under the poverty line, though the poverty gap substantially declines. Achievement of the lower targets has different effects in the two districts with respect to the medial poor households, i.e., it would enable them to be above the poverty line in Baso Liben, but it wouldn't do the same in Halaba. Again, households in the ultra-poor stratum would remain under the poverty line.

\section{Time Considerations}

Based on the pieces of information discussed in section "Time and Adoption", we made three important assumptions in conducting our analysis: (1) the maximum 


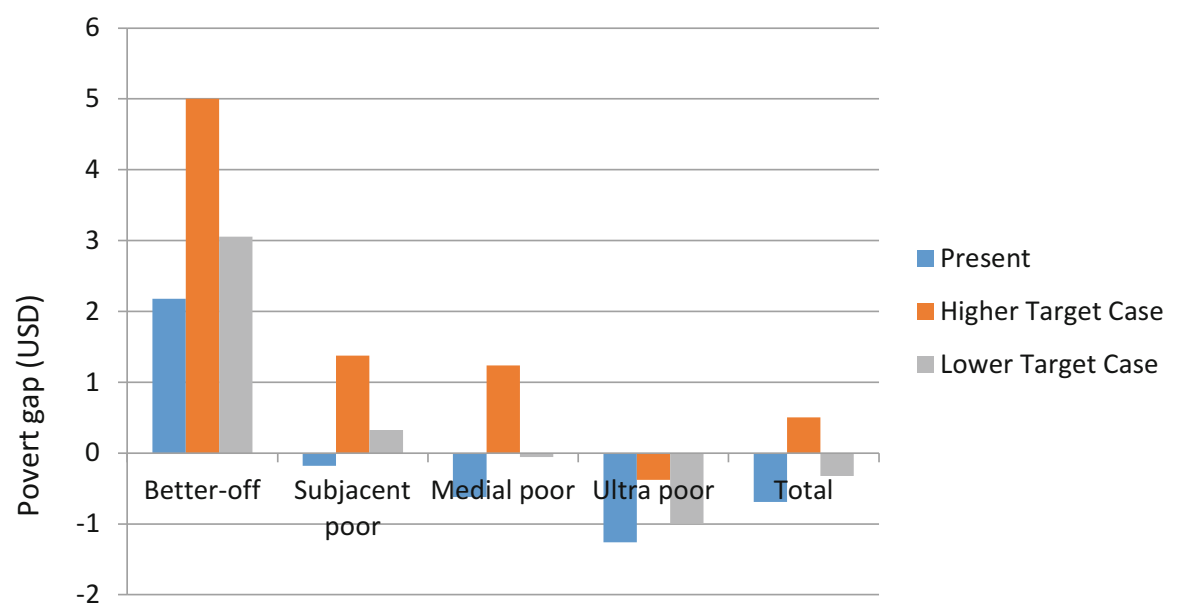

Fig. 20.2 Potential impacts of adoption of YICT on poverty reduction in Halaba

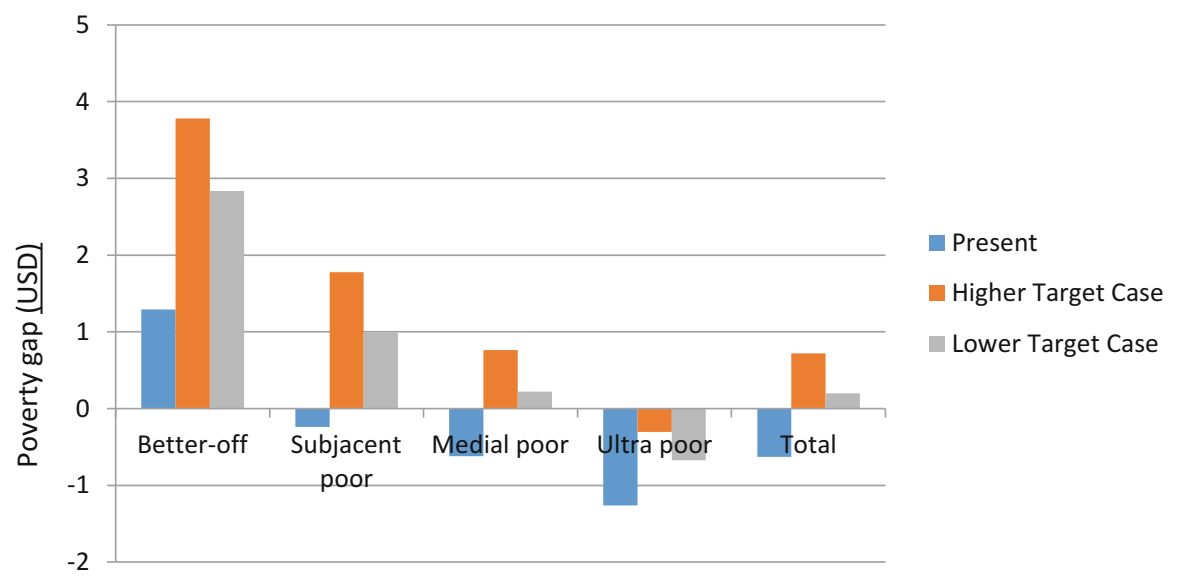

Fig. 20.3 Potential impacts of adoption of YICT on poverty reduction in Baso Liben

adoption rate is $90 \%$, (2) the maximum rate of adoption would be reached within 20 years after first introduction, and (3) about $80 \%$ of the change would occur during the last 10 years. In regards to the speed of adoption, the above assumption can be considered as a "typical case scenario", as we dub it. We also considered another scenario in our computation, which could be called an "accelerated case scenario", whereby the maximum adoption would be reached within 10 years. The accelerated case scenario assumes that an efficient extension system would exist, while it requires a higher commitment of the government and non-state actors to realize the targets. Given the current ambition of the Ethiopian government to increase crop productivity by about $30 \%$ in 2014/2015 (MoFED 2010) and the 


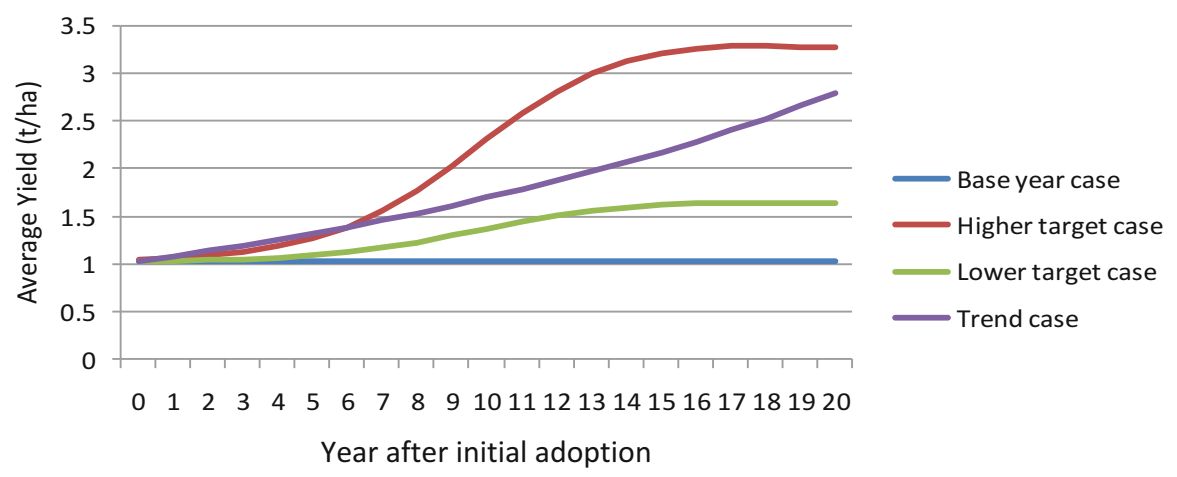

Fig. 20.4 Average grain yield of targeted crops in Halaba, typical case scenario

massive movements going on at grassroot levels to enhance adoption of improved agricultural technologies, it seems that the accelerated case scenario would be a plausible option for analysis.

The simulation results are displayed in Figs. 20.4, 20.5, 20.6, and 20.7. The results further assume that (1) all farmers will have access to extension services, (2) cropping patterns, and thus, land allocation among smallholders for the target crops, remain unchanged over time, (3) the growth rate of area under cereal production will be similar to that of the past 10 years (i.e., $1.26 \%$ ); and (4) the growth rate of the rural population will be similar to that of the past 10 years (i.e., a declining trend starting from $1.7 \%$ in 2014).

The average yield of the target crops would potentially increase from about $1 \mathrm{t} /$ ha at present to about $3.3 \mathrm{t} / \mathrm{ha}$ in Halaba and from about $1.6 \mathrm{t} / \mathrm{ha}$ to about $3.8 \mathrm{t} / \mathrm{ha}$ in Baso Liben under the typical scenario. This would happen when the HTC is realized, which will also lead to a rise in per capita grain production from 0.3 to $0.7 \mathrm{t}$ in Baso Liben and from 0.2 to $0.6 \mathrm{t}$ in Halaba. If the LTC is to be achieved, the average yield would rise from about 1 to $1.6 \mathrm{t} / \mathrm{ha}$ in Halaba and from about $1.6 \mathrm{t} / \mathrm{ha}$ to about $2.4 \mathrm{t} / \mathrm{ha}$ in Baso Liben. In this case, the per capita grain production would increase from 0.2 to $0.3 \mathrm{t}$ in Halaba and from 0.3 to $0.5 \mathrm{t}$ in Baso Liben. This would happen within two decades. The growth in grain productivity is expected to be faster under the accelerated scenario. In this case, the average yield would increase from about 1.2 to $3.9 \mathrm{t} / \mathrm{ha}$ in Halaba and from 1.7 to $4.1 \mathrm{t} / \mathrm{ha}$ in Baso Liben within a decade, provided that the higher target is achieved. This would also result in a rise of per capita grain production from 0.2 to $0.6 \mathrm{t}$ in Halaba and from 0.3 to $0.8 \mathrm{t}$ in Baso Liben. If the lower target is to be realized, the average yield would increase from 1 to $1.8 \mathrm{t} / \mathrm{ha}$ in Halaba and from 1.7 to $2.5 \mathrm{t} / \mathrm{ha}$ in Baso Liben. This would increase per capita production of the targeted crops from 0.2 to $0.3 \mathrm{t}$ in Halaba and from 0.3 to $0.5 \mathrm{t}$ in Baso Liben.

The figures also display projected actual yields based on the trend of average yield of the target crops in the past 10 years. The latter case shows what will happen to the average yield of the target crops if the current trend continues until the end of the projection period. The LTC can be reached within 10 years in Halaba and within 9 years in Baso Liben if average yield grows at the pace of the past 10 years. This 


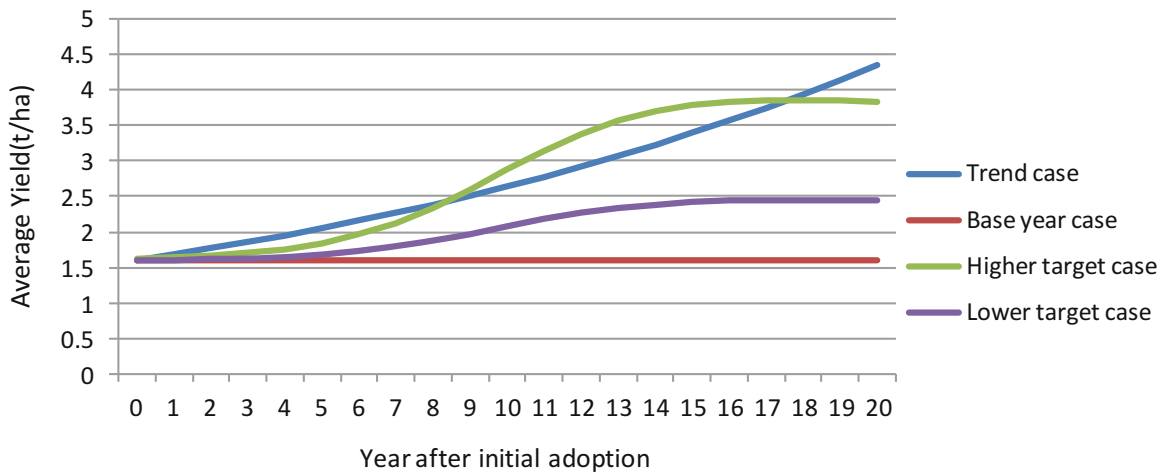

Fig. 20.5 Average grain yield of targeted crops in Baso Liben, typical case scenario

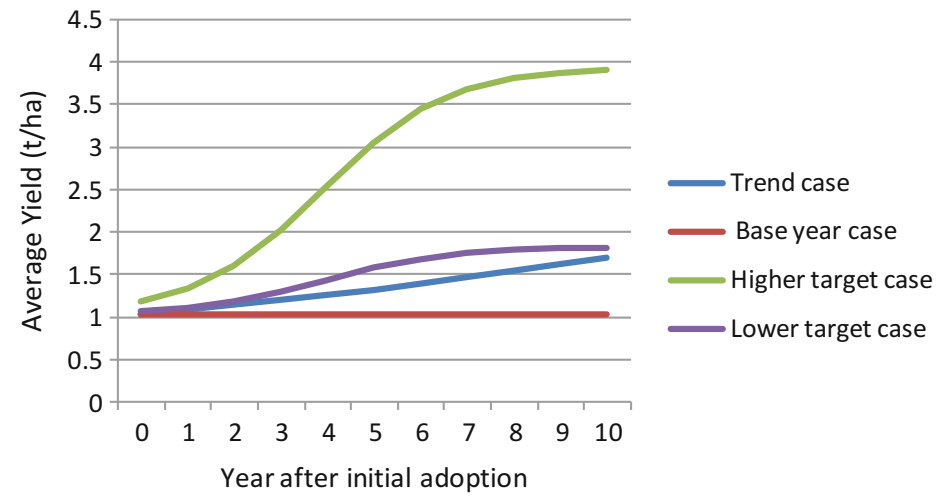

Fig. 20.6 Average grain yield of targeted crops in Halaba, accelerated case scenario

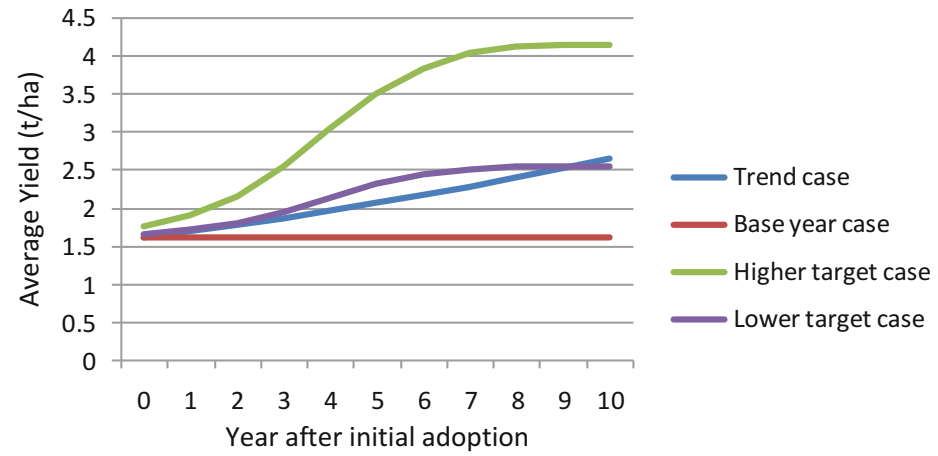

Fig. 20.7 Average grain yield of targeted crops in Baso Liben, accelerated case scenario 
implies that no additional effort is needed to achieve the LTC under the typical case scenario, further implying that the extension system is doing well. However, sustaining the current productivity growth for the coming decade requires additional efforts by itself, which may include promoting the YICT proposed in this paper. The growth paths produced by our model to achieve the higher yield targets deviate considerably from the forecasted trend line, implying that more efforts should be made (than are being made at present) to realize these targets, even within two decades. There would be a better possibility of reaching the targets within the stated time in Baso Liben than in Halaba. Under the accelerated case scenario, it is assumed that the targets would be reached within a decade and the impacts of the YICT on the livelihoods of smallholders would be realized faster. If the growth rate of the past decade is sustained in the coming 10 years, only $47 \%$ of the target average yield in Halaba and about $64 \%$ of the target average yield in Baso Liben will be achieved, which implies that the higher target cannot be reached unless the pace of the past decade is substantially improved. Thus, innovative strategies need to be implemented to achieve the higher targets. However, the lower targets can be reached given the existing pace of growth.

The mean discounted net benefits were analyzed taking into account a time horizon of 20 years regarding the use of target YICT. ${ }^{25}$ The main results are displayed in Figs. 20.8, 20.9, 20.10, and 20.11, whereas the patterns of change over the period considered are displayed in Figs. A1 to A2 in the annex. The results further assume that (1) the costs of dissemination of the technologies are sunk costs which will not change because of the introduction of these technologies, and (2) there will be adequate demand for outputs, and increasing production will not have negative effects on output prices.

If we consider the "typical" scenario of adoption, the mean net benefit per year for all farmers in both study areas over the stated period is 135.2 million birr, provided that the higher target is achieved; the net benefit would be about 71 million birr if the lower target is to be achieved (Fig. 20.8). Under the "accelerated" scenario, the mean figure would be 181.7 million birr for the HTC and 94.9 million birr for the LTC (Fig. 20.9). There is a visible difference between the two districts, Baso Liben taking a better position. The mean per capita net benefit corresponding to the HTC is $9.8 \mathrm{birr} /$ day under the typical scenario, while it is $13.4 \mathrm{birr} /$ day under the accelerated scenario (Fig. 20.10). The figures corresponding to the LTC are 5.1 and 7 birr/day under the typical and accelerated scenarios, respectively (Fig. 20.11). Overall, the adoption of the YICT will have a total net benefit of about 2.8 and 3.8 billion birr under the typical and accelerated scenarios, respectively, over the entire planning horizon, provided that the higher target case is realized. The figures corresponding to the two scenarios would be 1.5 and 2 billion birr if the lower target is to be achieved. ${ }^{26}$

\footnotetext{
${ }^{25}$ An annual inflation rate of $12.3 \%$ was considered to simulate future prices. This figure is an average figure for the last 16 years.

${ }^{26}$ The net benefits from the YICT under consideration may decline because some varieties may not cope well with new pest out-breaks or because of other reasons. However, it is expected that farmers would keep the momentum of existing high yield or increase it by adopting better varieties and, thus, the trend will at least level off after the maximum point.
} 


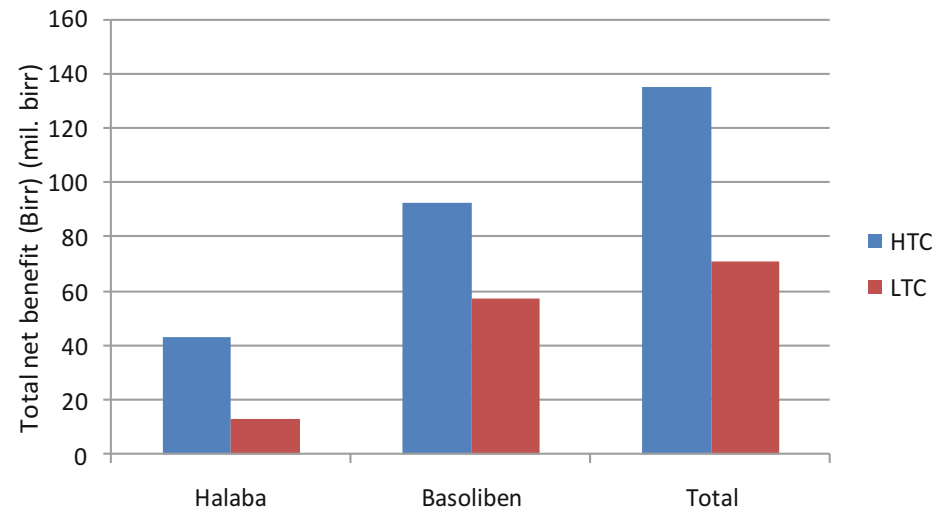

Fig. 20.8 Average discounted total net benefit (for all farmers), typical scenario (in million birr)

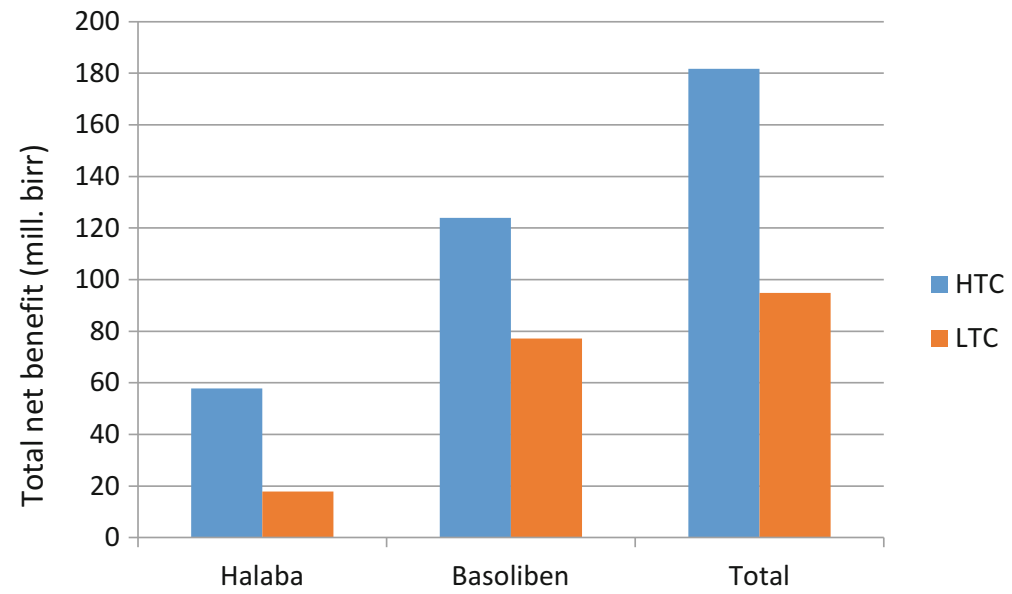

Fig. 20.9 Average discounted total net benefit (for all farmers), accelerated scenario (in million birr)

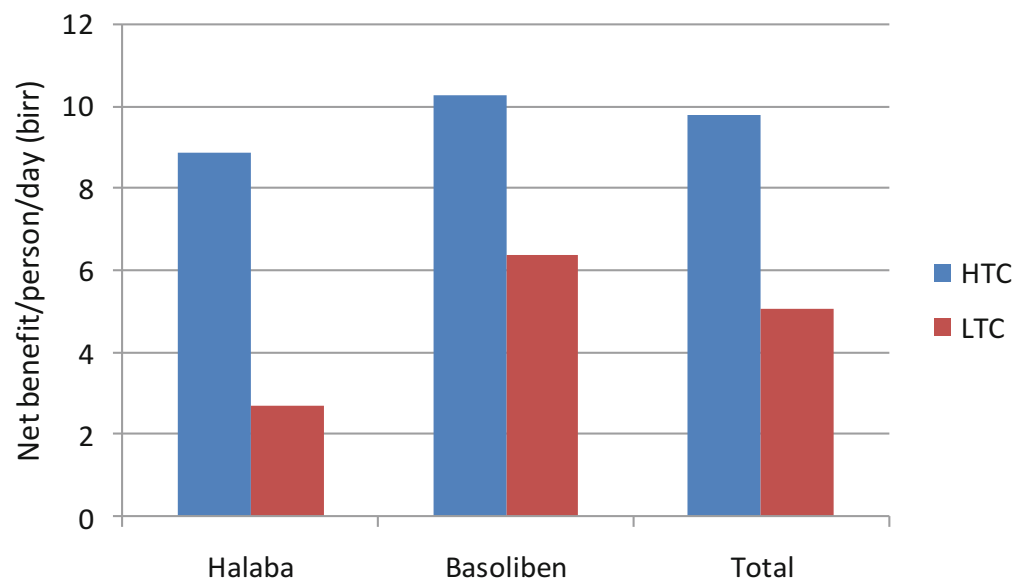

Fig. 20.10 Discounted net per capita benefit per day (birr), typical scenario 


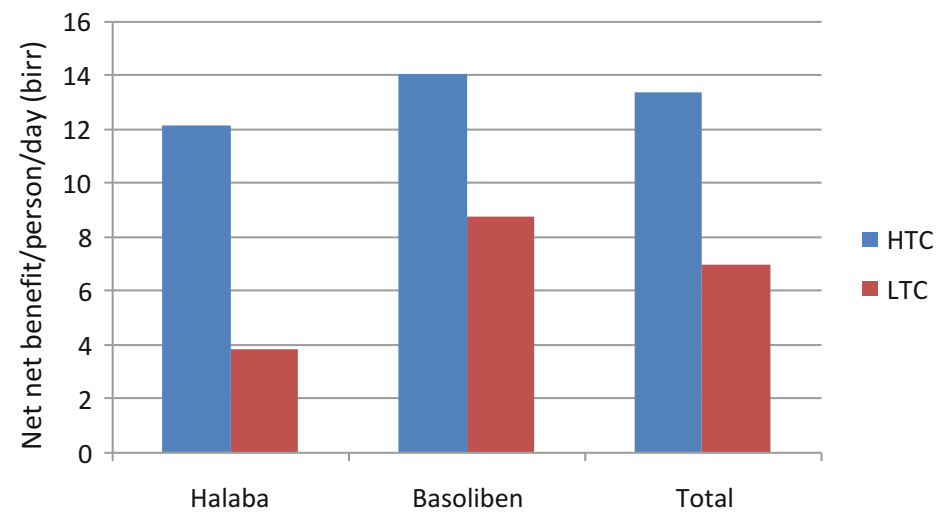

Fig. 20.11 Discounted net per capita benefit per day (birr), accelerated scenario

\section{Conclusions}

This study assessed the potential impact of existing yield-increasing crop technologies on productivity and poverty. Results are based on household survey data collected from two districts of Ethiopia, namely: the Halaba special district in the Southern Nations, Nationalities, and Peoples Region (SNNPR) and the Baso Liben district in the Amhara Region. The two districts were selected for showing high agricultural potential while being marginalized.

Results indicate that about $90 \%$ of farm households are poor and food insecure in these areas. Adoption of yield increasing crop technologies is low, resulting in low productivity and income. Our results show that adoption of agricultural technologies (namely improved seeds with appropriate agronomic packages) would increase yields and incomes substantially, thereby reducing poverty. The average net benefit per household is about 17,000 birr in Halaba and nearly 18,000 birr in Baso Liben, assuming that technologies produce yields as indicated by reports of on-farm yield trials. The total net benefit per district ranges from 71 to 182 million birr per year, while the net additional benefit per person per day ranges from 5 to 13 birr. These amounts of additional benefit would be enough to lift up the subjacent poor and the medial poor out of poverty in both districts. However, the amounts would not be sufficient for the ultra-poor to shift above the poverty line considered in this analysis, which implies that other options (such as promoting non-farm rural businesses) would be required to lift these households out of poverty. These are rough results to the extent that the future is uncertain in terms of prices, technologies, climate. Nevertheless, the overall implication of the study is that the benefits from proposed crop technologies would be high, with the potential of reducing poverty significantly. 
Open Access This chapter is distributed under the terms of the Creative Commons AttributionNoncommercial 2.5 License (http://creativecommons.org/licenses/by-nc/2.5/) which permits any noncommercial use, distribution, and reproduction in any medium, provided the original author(s) and source are credited.

The images or other third party material in this chapter are included in the work's Creative Commons license, unless indicated otherwise in the credit line; if such material is not included in the work's Creative Commons license and the respective action is not permitted by statutory regulation, users will need to obtain permission from the license holder to duplicate, adapt or reproduce the material.

\section{Annex}

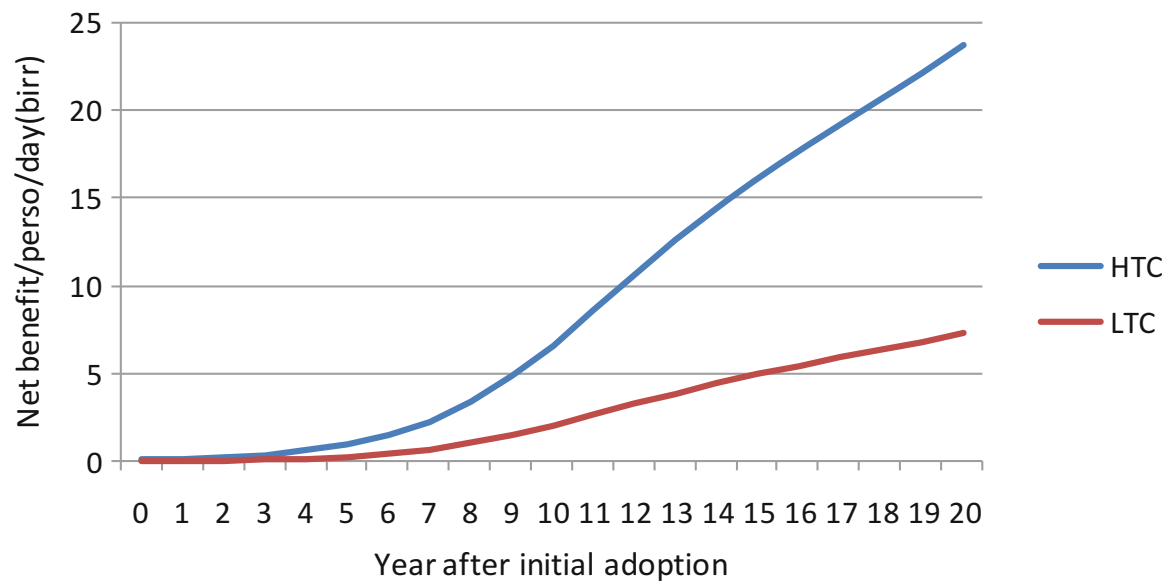

Fig. A.1 Per capita additional net benefit per day from adopting YICT in Halaba, typical case scenario

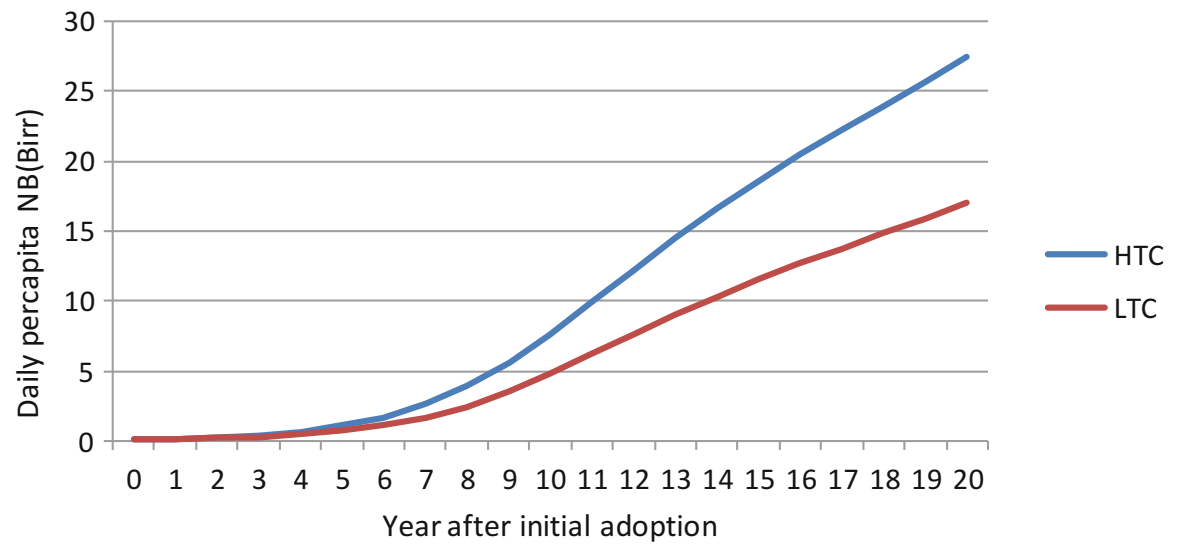

Fig. A.2 Per capita additional net benefit per day from adopting YICT in Baso Liben, typical case scenario 


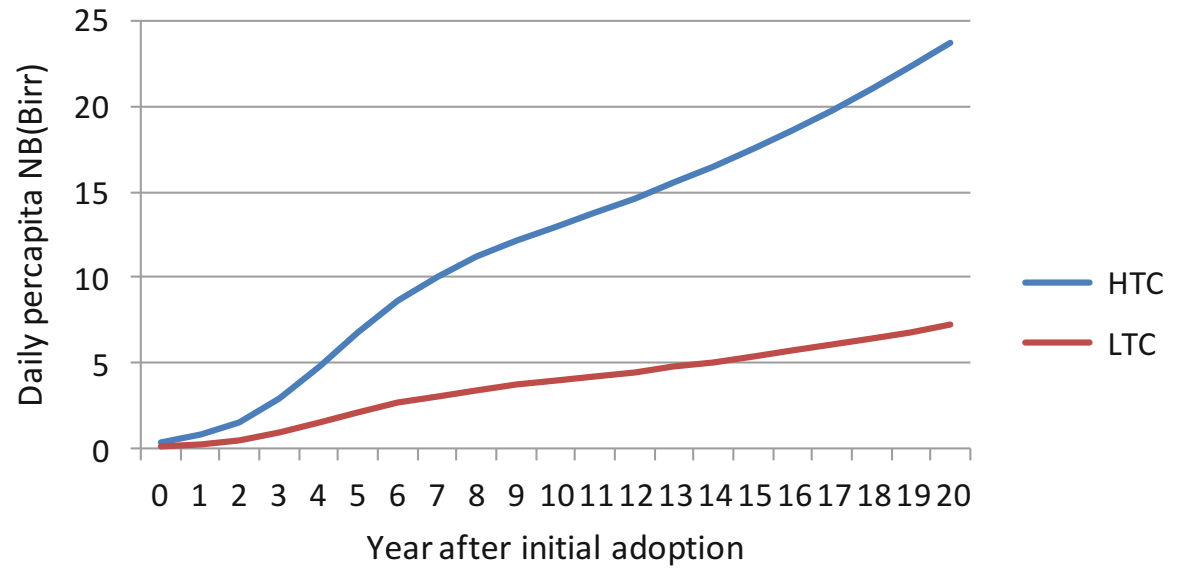

Fig. A.3 Per capita additional net benefit per day from adopting YICT in Halaba, accelerated case scenario

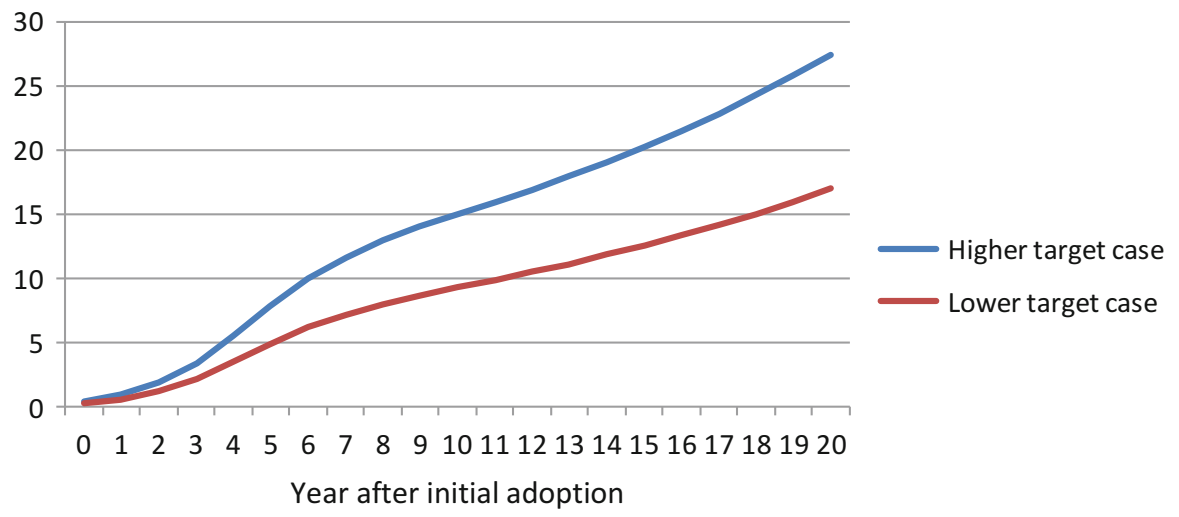

Fig. A.4 Per capita additional net benefit per day from adopting YICT in Baso Liben, accelerated case scenario

\section{References}

Ahmed AU, Vargas Hill R, Smith LC, Wiesmann DM, Frankenberger F (2007) The world's most deprived: characteristics and causes of extreme poverty and hunger. International Food Policy Research Institute, Washington, DC

Alston JM, Norton GW, Pardey PG (1995) Science under scarcity. Cornell University Press, Ithaca ATA (2012) Five year seed sector strategy document, draft. Ethiopian Agricultural Transformation Agency, Addis Abeba

Bera AK, Kelley TG (1990) Adoption of high yielding rice varieties in Bangladesh: an econometric analysis. J Dev Econ 33:263-285

CIMMYT (1988) From agronomic data to farmers recommendation: an economics training manual, completely revised. International Maize and Wheat Improvement Center, Mexico 
CSA (2011a) Report on farm management practices (private peasant holdings, meher season), statistical bulletin 505. Central Statistical Agency, Addis Abeba

CSA (2011b) Report on area and production of major crops (private peasant holdings, meher season). Central Statistical Agency, Addis Abeba

CSA (2012) Agricultural sample survey 2011/12, Report on land utilization, private peasant holdings, meher season, Bulletin No 532. Central Statistical Agency, Addis Abeba

Davies S (1979) The diffusion of process innovations. Cambridge University Press, Cambridge

Diao X, Seyoum Taffesse A, Yu B, Nin Pratt A (2010) Economic importance of agriculture for sustainable development and poverty reduction: the case study of Ethiopia, Global forum on agriculture. Organisation for Economic Co-operation and Development, Paris

Ephraim M, Featherstone AM (2001) Cross pollinated crop variety adoption studies and seed recycling: the case of maize in Tanzania. East Afr J Rural Dev 17(1):25-34

FAOSTAT (2013) http://faostat.fao.org, accessed Jul 22, 2014

Gatzweiler F, Baumüller H, Ladenburger C, von Braun J (2011) Marginality: addressing the root causes of extreme poverty, ZEF Working paper series No. 77. Center for Development Research, Bonn

Graw V, Ladenburger C (2012) Mapping marginality hotspots: geographical targeting for poverty reduction, ZEF Working paper series No. 88. Center for Development Research, Bonn

Hailu BA (2008) Adoption of improved tef and wheat production technologies in crop-livestock mixed systems in northern and western Shewa zones of Ethiopia thesis. University of Pretoria, Pretoria

Hareau GG, Mills BF, Norton GW (2006) The potential benefits of herbicide-resistant transgenic rice in Uruguay: lessons for small developing countries. Food Policy 31:162-179

Hazell PBR (2009) The Asian green revolution. IFPRI Discussion Paper 00911

Hundie B (2012) The current state of agriculture in Ethiopia: productivity, technology innovations, technology reach and food security. A background paper prepared for TIGA project kick-off meeting. Center of Development Research, Bonn

Hundie Kotu B, Verkuijl H, Mwangi W, Tanner D (2000) Adoption of improved wheat technologies in Adaba and Dodola Woredas of the Bale Highlands, Ethiopia. International Maize and Wheat Improvement Center and Ethiopian Agricultural Research Organization, Mexico/Addis Abeba

Krishna VV, Qaim M (2008) Potential impacts of Bt eggplant on economic surplus and farmers' health in India. Agri Econ 38:167-180

Macharia I, Orr A, Simtowe F, Asfaw S (2012) Potential economic and poverty impacts of improved chickpea technologies in Ethiopia. A selected paper prepared for presentation at the International Association of Agricultural Economists (IAAE) Triennial Conference, Foz do Iguaçu, 18-24 Aug 2012

Mahajan V, Peterson RA (1978) Innovation diffusion in a dynamic potential adopter population. Manag Sci 24:1589-1597

MOA (2011) Crop variety register, vol 14. Ministry of Agriculture, Addis Ababa

MoFED (2010) Growth and transformation plan (2010/11-2014/15), vol I. Ministry of Finance and Economic Development, Addis Ababa

MoFED (2012) Ethiopia's progress towards eradicating poverty: an interim report on poverty analysis study (2010/11). Ministry of Finance and Economic Development, Addis Ababa

Mosher TA (1979) An introduction to agricultural extension. Singapore University Press for the Agricultural Development Council, Singapore

Motuma T, Dejene A, Wondwossen T, La Rovere R, Girma T, Mwangi W, Mwabu W (2010) Adoption and continued use of improved maize seeds: case study of Central Ethiopia. Afr J Agric Res 5(17):2350-2358

Napasintuwong O, Traxler G (2009) Ex-ante impact assessment of GM papaya adoption in Thailand. AgBioForum 12(2):209-217

Qaim M (2003) Bt cotton in India: field trial results and economic projections. World Dev 31 (12):2115-2127

Rogers E (1983) Diffusion of innovations. Free Press, New York 
Tesfaye Z, Girma T, Tanner D, Vekuijl H, Aklilu E, Mwangi W (2001) Adoption of improved bread wheat varieties and inorganic fertilizers by small-scale farmers in Yilmana Densa and Farta Districts of Northwestern Ethiopia. Ethiopian Agricultural Research Organization and International Maize and Wheat Improvement Center, Addis Abeba/Mexico

von Braun J, Hill RV, Pandya Lorch R (2009) The poorest and hungry: a synthesis of analyses and actions. In: The poorest and hungry. Assessment, analyses, and actions. IFPRI 2020. International Food Policy Research Institute, Washington, DC, pp 1-61 